\title{
Influence of zinc deficiency on one year recurrence in children with nephrotic syndrome
}

\author{
Fatemeh Ghafoorimehr, Mastaneh Moghtaderi* ${ }^{\circledR}$, Behnaz Bazargani, Dariush Fahimi, Arash Abbasi \\ Children Medical Center Hospital, Tehran University of Medical Science, Tehran, Iran
}

\section{A R T I C L E I N F O}

Article Type:

Original

Article History:

Received: 13 March 2019

Accepted: 27 May 2019

Published online: 14 June 2019

Keywords:

Nephrotic syndrome

Zinc deficiency

Recurrence

Children

\begin{abstract}
A B S T R A C T
Introduction: Relapses in children with steroid sensitive nephrotic syndrome (SSNS) are common and sometimes triggered by various infections. Low zinc levels have been described in children with nephrotic states. It is supposed to that zinc deficiency might lead to dysregulation of immune system and an increased risk of infection.

Objectives: This study sought to examine whether the plasma level of zinc in nephrotic patients is related to the number of relapses in these patients.

Patients and Methods: Forty-three children aged 1-10 years were entered in this study. Baseline data including age, serum zinc level, number of relapses during one year was recorded. The $t$ test and chi-square tests were used to compare the mean values and proportions respectively with significant $P$ value $(P<0.05)$.

Results: Forty-three children with storied sensitive nephrotic syndrome enrolled in this study. Twenty-three (53.5\%) of them were male and 20 (46.5\%) were female. Around 74.4 $\%$ of patients experienced relapses of nephrotic syndrome in one-year period. There was a significant relation between zinc deficiency and recurrence rate.

Conclusion: Zinc deficiency is common in children suffering from nephrotic syndrome and is related to recurrence of relapses in these patients.
\end{abstract}

Implication for health policy/practice/research/medical education:

Our study on 43 children with storied sensitive nephrotic syndrome showed that recurrence in nephrotic patients has a relationship between low plasma zinc levels. We suggest zinc supplementation in these patients along with standard steroid therapy.

Please cite this paper as: Ghafoorimehr F, Moghtaderi M, Bazargani B, Fahimi D, Abbasi A. Influence of zinc deficiency on one year recurrence in children with nephrotic syndrome. J Renal Inj Prev. 2019;8(3):243-246. DOI: 10.15171/jrip.2019.46.

\section{Introduction}

Nephrotic syndrome (NS) characterized by massive proteinuria, decreased serum albumin level and peripheral edema is a common childhood disease with chronic relapsing course. In $80 \%-85 \%$ of affected children called as steroid sensitive nephrotic syndrome (SSNS) the response to steroid therapy is very good but in the remaining $15 \%-20 \%$ of patients there is no response to steroids called as steroid resistant nephrotic syndrome (SRNS) (1). Steroid therapy improves proteinuria in the first group, but even in this group of patients who have this initial good response, in 40\%-50\% of patients, the disease becomes steroid dependent eventually or there is frequent relapses commonly following an infectious episode (2). There are an increased risk of serious complications such as sepsis, thrombosis, dyslipidemia and malnutrition during or following each relapse (3). The mechanism of steroid responsiveness or infections that trigger relapses is unclear. Disturbed cell-mediated immunity reactions and an association with atopic state, high serum $\operatorname{IgE}$ and upregulated gene-expression of interleukin 4 (IL4), since interleukin13 (IL-13) proposes type-2 cytokine disturbance in these patients that may be affected by serum zinc level (4).

Zinc is a trace element in our body and is essential in protein synthesis and normal cell growth and differentiation. Zinc deficiency most commonly affects epidermal integrity, gastrointestinal, central nervous system, immune function, skeletal, and reproductive organs (5). It is present in nearly all of tissues, especially the thyroid gland, pancreas, and reproductive organs and is involved in most of the body's enzymatic processes, 
protein synthesis and carbohydrate metabolism. Serum zinc is mostly protein bounded, $50 \%$ of plasma zinc is bound to albumin and the remaining is bound to other plasma proteins (6).

Low plasma zinc level occurs in severe malnutrition, malabsorption and nephrotic states, due to lack or decreased intake, decreased bowel absorption or increased loss of zinc in diarrheal state or in urine in association with proteins or albumin. It seems that zinc supplementation theoretically can reduce morbidity and mortality, especially among children with gastrointestinal and respiratory problems (7). It is suggested that zinc deficiency can lead to down-regulation of T- helper 1 cytokines, resulting in a relative T-helper 2 cell over activity and an increased risk of clinical infections (8). Zinc supplementation may result in restoration of Th1 immune response through suggested augmentation of gene expression for IL- 2 and interferon- $\alpha$ (9). The Th1/Th2 cytokine imbalance is believed to be implicated in relapses of SSNS (10). Zinc is an intrinsic metal component or an activating cofactor for more than 70 important enzymatic reactions, including carbonic anhydrases, alkaline phosphatases, dehydrogenases and carboxypeptidases. It is also involved in the regulation of nucleoproteins and the reactivity of cell-mediated immunity, and body response to infections and plays an important role in body growth, tissue repair and healing of the wounds, carbohydrate tolerance, and also synthesis of male hormones.

There is impaired phagocytic function, lymphocyte depletion, decreased immunoglobulin production, a reduction in the $\mathrm{T} 4+/ \mathrm{T} 8+$ ratio and decreased interleukin (IL)-2 production in zinc deficiency (11).

\section{Objectives}

This study aimed to evaluate whether the plasma level of zinc in nephrotic patients is related to the number of relapses in these patients.

\section{Patients and Methods \\ Patients}

This study was conducted in department of pediatrics nephrology of children medical center (January 2017 to October 2018). All children aging 1-10 years attending the outpatient department and all hospitalized children admitted in nephrology department diagnosed as nephrotic syndrome were included in this study. NS was diagnosed according to bedside urine protein level in range of $3+$ to $4+$ (significant nephrotic range proteinuria $40 \mathrm{mg} / \mathrm{m}^{2} / \mathrm{h}$ ), hypoalbuminemia (serum albumin $<2.5$ $\mathrm{g} / \mathrm{dL}$ ) and hyperlipidemia (serum cholesterol $>200 \mathrm{mg} /$ $\mathrm{dL}$ ) and known cases of SSNS that did not receive any zinc supplement or immunosuppressive drugs except prednisolone.

Children with SRNS, patients less than one year or over 10 years, taken zinc therapy within the last 3 months, nephrotic syndromes with secondary causes, and patients who refuse from giving consent to our study were excluded. Baseline data including age, gender, history of atopy and familial history of nephrotic syndrome and high blood pressure, clinical signs of edema, ascites and para-clinical findings such as serum albumin, cholesterol, electrolytes, calcium, sodium, potassium, creatinine, blood urea. Urinary protein to creatinine ratio was recorded at the time of diagnosis and serum zinc level calculated when the patients reached the remission phase. According to the references of our laboratory, normal zinc level was 78-110 $\mathrm{mg} / \mathrm{dL}$. The patients were followed at least for one year since all relapses were recorded.

\section{Ethical issues}

The research followed the tents of the Declaration of Helsinki. The Ethics Committee of Tehran University of Medical Sciences approved this study. Written informed consent was obtained from patients' parents. All procedures performed in this study involving human participants were in accordance with the ethical standard of the Tehran University of Medical Science with an approval number of IR.TUMS.CHMC.REC.1396.4520. This study was conducted as a thesis by Fatemeh Ghafoorimehr in nephrology ward of pediatric department of Tehran University of Medical Sciences, Tehran, Iran.

\section{Results}

A total of 43 children with storied sensitive nephrotic syndrome enrolled in this study. Twenty-three (53.5\%) of them were male and $20(46.5 \%)$ were female. The mean age was $6.5 \pm 3.7$ years. None of them had familial history of nephrotic syndrome. There was history of allergic (food, skin or respiratory) reactions in 37.2 percent of patients. All of patients had edema but $53 \%$ of them had ascites at diagnosis. Regarding recurrence 11 (25.6\%) of patients had no recurrence in the first year of study. The recurrence rate of nephrotic syndrome in the first year is shown in Table 1. Recurrence rate of each case is shown in Table 2.

Several variables were studied including serum cholesterol, albumin, and zinc and also protein/creatinine ratio. In relation to serum zinc level three levels were defined; bellow $78 \mathrm{mg} / \mathrm{dL}$, between 78 to $110 \mathrm{mg} / \mathrm{dL}$ and above 110 $\mathrm{mg} / \mathrm{dL}$. Detailed rates of patients are shown in Table 3. The relation of serum zinc to age, recurrence rate, serum albumin, and cholesterol and protein/creatinine level was studied. According to one way study, no meaningful

Table 1. The recurrence rate of nephrotic syndrome in the first year

\begin{tabular}{lll}
\hline Valid & No. & $\%$ \\
\hline No & 11 & 25.6 \\
Yes & 32 & 74.4 \\
Total & 43 & 100.0 \\
\hline
\end{tabular}


Table 2. Recurrence rate of each case

\begin{tabular}{lcc}
\hline Valid & No. & $\%$ \\
\hline 0 & 11 & 25.6 \\
1 & 12 & 27.9 \\
2 & 7 & 16.3 \\
3 & 4 & 9.3 \\
4 & 4 & 9.3 \\
5 & 4 & 9.3 \\
6 & 1 & 2.3 \\
Total & 43 & 100.0 \\
\hline
\end{tabular}

Table 3. Serum zinc level of the patients $(\mathrm{mg} / \mathrm{dL})$

\begin{tabular}{lcc}
\hline Valid & No. & $\%$ \\
\hline$<78$ & 35 & 81.4 \\
$78-110$ & 7 & 16.3 \\
$>110$ & 1 & 2.3 \\
Total & 43 & 100.0 \\
\hline
\end{tabular}

relation between zinc and other variables except recurrence rate was seen. According to NPar test, recurrence rate was greater in those with lower than $78 \mathrm{mg} / \mathrm{dL}$ zinc level $(P=0.001)$. This finding shows that the recurrence rate was greater in these cases in one year period. Table 4 shows the relation of recurrence rate and serum zinc level. Table 5 shows relapses and its relation to different factors.

\section{Discussion}

Zinc is an essential trace element involved in protein synthesis, cell growth, and differentiation in the human body. Severe zinc deficiency is known to be associated with delayed growth, hypogonadism, impaired immune system function, skin problems, different cognitive disturbances and loss of appetite (7). Normal plasma zinc is about 70 to $110 \mathrm{mcg} / \mathrm{dL}$, of which 60 percent is loosely bound to albumin and 30 percent is tightly bound to macroglobulins. Urinary excretion typically is between 0.5 to $0.8 \mathrm{mcg} /$ day. The primary organs storing zinc are liver and kidneys since most of the zinc is as intracellular bounded to metalloproteins (8). Short term zinc supplementation ( 2 weeks) among children attempting to treat or preventing common childhood infections was found to be beneficial (9).

Cogan et al observed an increased urinary excretion of high density lipoproteins and of transporting proteins of iron, copper and zinc in patients with nephrotic syndrome. Not only the transport proteins are lost in urine but also there is an increased excretion of these trace elements (12). Zinc supplement may lead to decreased episodes of infections presumably due to augmentation of gene expression for IL-2 and interferon, thereby restoring the cytokine-1 immune responses. Zinc deficiency is quite common and is associated with a high mortality in
Table 4. Relationship of serum zinc level and recurrence rate ( $\mathrm{mg} / \mathrm{dL})$

\begin{tabular}{lccc}
\hline Serum zinc level & Number & Mean rank & Sum of ranks \\
\hline$<78$ & 35 & 24.29 & 850 \\
$78-110$ & 7 & 7.57 & 53 \\
Total & 42 & & \\
\hline
\end{tabular}

Table 5. Relapses and its relation with different factors

\begin{tabular}{lcccc}
\hline Relapse & $\mathbf{N}$ & Mean & SD & Significance (2-tailed) \\
\hline Age & & & & 0.669 \\
No & 11 & 6.9845 & 4.39083 & \\
Yes & 32 & 6.4112 & 3.60231 & 0.228 \\
Albumin & & & & \\
No & 11 & 2.0182 & 0.35726 & \\
Yes & 32 & 1.8594 & 0.37577 & \\
Cholesterol & & & & \\
No & 11 & 344.82 & 81.902 & 0.697 \\
Yes & 32 & 347.25 & 96.437 & \\
Protein & & & & \\
No & 11 & 13.9573 & 10.69755 & \\
Yes & 32 & 12.6759 & 8.87248 & \\
Zinc & & & & \\
No & 11 & 80.373 & 12.0983 & \\
Yes & 32 & 61.309 & 20.2607 & \\
\hline
\end{tabular}

developing countries (13). In our study 11 patients did not have any relapse of nephrotic syndrome in one year follow up since all of them had zinc level up to $110 \mathrm{mcg} /$ $\mathrm{dL}$ (normal range). There is a meaningful relationship between serum zinc level and relapse of nephrotic syndrome. Kumar et al showed that zinc therapy is effective in remission induction of pediatric nephrotic syndrome. Mean number of days taken in remission in patients received zinc supplement were $11.8 \pm 3.96$ days while in control group were $18.3 \pm 5.14$ days. The hospitalization time in nephrotic patients that received zinc supplement was shorter than other patients (14).

Sherali et al studied the effect of decreased plasma zinc on the relapse rates in 54 children with SSNS. Sixty children aging between 2 to 15 -year-old were selected and the relapse rate in one year was recorded. At last 54 cases completed the study while there was no meaningful difference in relapse rates in respect to serum zinc level at first year. However, after this time in those children who received supplemental zinc, the relapse rate was meaningfully lower (7\% versus 10\%) than others. They concluded that receiving supplemental zinc can reduce relapses in the course of nephrotic syndrome (13).

Bhatt et al performed a randomized controlled trial study on the effect of zinc versus placebo on recurrences and number of infection in SSNS. They prescribed zinc 
supplement to one group for 6-12 months and compared with the placebo group. They established that addition of zinc to standard treatment of nephrotic syndrome is effective in decreasing of infections and recurrences. (15) Our study also showed that recurrences in nephrotic patients have a relationship between low plasma zinc levels.

\section{Conclusion}

Our study showed that serum zinc level was low in nephrotic patients and there is a direct relation between low zinc levels. We suggest zinc supplementation in these patients along with standard steroid therapy.

\section{Limitations of the study}

Our study was conducted on a limited proportion of patients. We suggest investigating the serum zinc level in the future similar studies.

\section{Authors' contribution}

MM and FG conceived the study and designed the project idea. DF, AA and BB grandly supported and provided us their patients to be included in the study. All authors read, revised and approved the final manuscript.

\section{Conflicts of interest}

The authors declare no conflict of interest.

\section{Ethical considerations}

Ethical issues (including plagiarism, data fabrication, double publication) have been completely observed by the authors.

\section{Funding/Support}

This research had no financial support.

\section{References}

1. Santín S, Bullich G, Tazón-Vega B, García-Maset R, Giménez I, Silva I, et al. Clinical utility of genetic testing in children and adults with steroid-resistant nephrotic syndrome. Clin J Am Soc Nephrol. 2011;6:1139-1148.

2. Niaudet P, Boyer O. Idiopathic nephrotic syndrome in children: clinical aspects. In: Avner ED, Harmon WE, Niaudet PYoshikawa N, eds. Pediatric Nephrology. 6th ed. Berlin: Springer 2009. p. 667-702.

3. Webb NJA. Epidemiology and general management of childhood idiopathic nephrotic syndrome. In: Molony D, Craig J, eds. Evidence-based Nephrology. Oxford, UK: Wiley-Blackwell; 2008.

4. Mathieson PW. Immune dysregulation in minimal change nephropathy. Nephrol Dial Transplant. 2003;18:26-9.

5. Fukushima T. The role of zinc in chronic kidney disease. Nihon Rinsho. 2016;74:1138-43.

6. Haque F, Hanif M, Choudhury TR. Role of zinc in patients with nephrotic syndrome. J Ped Nephrol. 2017;5:1-7.

7. Aggarwal R, Sentz J, Miller MA. Role of zinc administration in prevention of childhood diarrhea and respiratory illnesses: a meta-analysis. Pediatrics. 2007; 119:1120-30.

8. Canani RB, Cirillo P, Buccigrossi V. Zinc inhibits cholera toxin-induced, but not Escherichia coli heat-stable enterotoxin-induced, ion secretion in human enterocytes. J Infect Dis. 2005;191:1072.

9. Prasad AS. Zinc: mechanisms of host defense. J Nutr. 2007; 137:1345-49.

10. Prasad AS. Effects of Zinc deficiency on Th1 and Th2 cytokine shifts. J Infec Dis. 2000;182:S62-8.

11. Hambidge KM, Krebs NF. Zinc deficiency: a special challenge. J Nutr. 2007;137:1101.

12. Bagga A, Sinha A, Srivastava RN. Disorders of kidney and urinary tract. In: Paul VK, Ghai BA, eds. Essential Pediatrics 8th ed. New Delhi: CBS publishers and Distributors; 2013:477.

13. Sherali AR Mooran KM, Chishty SH, Khan SI. Zinc supplement in reduction of relapses in children with steroid sensitive nephrotic syndrome. J Coll Physic Surg Pak. 2014; 24:110-3. doi: 02.2014/JCPSP.110113.

14. Kumar D, Arya P Sharma IK, Singh MV. Effect of zinc therapy in remission of pediatric nephrotic syndrome. Int Cont Ped. 2017;4:2036-2040. doi: 10.18203/2349-3291. ijcp20174726.

15. Bhatt GC, Jain S, Das RR. Zinc supplementation as an adjunct to standard therapy in childhood nephrotic syndrome - a systematic review. World J Clin Pediatr. 2016; 5:383-90.

Copyright (c) 2019 The Author(s); Published by Nickan Research Institute. This is an open-access article distributed under the terms of the Creative Commons Attribution License (http://creativecommons.org/licenses/by/4.0), which permits unrestricted use, distribution, and reproduction in any medium, provided the original work is properly cited. 